\title{
For the Great Leap of Psychiatry Investigation
}

\author{
Hyun Kook Lim, Editor-in-Chief \\ Department of Psychiatry, Yeouido St. Mary's Hospital, College of Medicine, The Catholic University of Korea, Seoul, Republic of Korea
}

I am Hyun Kook Lim, a new Editor-in-Chief of Psychiatry Investigation, and I salute to the readers, authors and reviewers of Psychiatry Investigation. While I am honored to inherit noble achievements the previous Editor-in-Chief Dr. Heon-Jeong Lee accomplished, I am with heavy hearts, being endowed with tremendous responsibilities of managing the journal. Journal of the Korean Neuropsychiatric Association (KNPA) is already well known as one of the oldest scholarly journals, and its distinguished history is closely bonded with the history of scholarly journals of Korea. Moreover, Psychiatry Investigation, the English journal of KNPA, has become a journal representing psychiatric research of the Asian region. The new editorial board of Psychiatry Investigation will endeavor to inherit invaluable heritages previous Editors-in-Chief built, and to lead the journal to a more progressive and productive direction.

Expediting the review process, adopting guest editor system, increasing the impact factor of Psychiatry Investigation and making Journal of KNPA an accredited journal of National Research Foundation are four major goals that have been set to improve the quality of the two journals of KNPA during the duty period (2020-2021). Psychiatry Investigation has suffered from a limited pool of reviewers, which led to variations of reviewing time and inefficient publishing process. To overcome this problem, I will attempt to expand the pool of reviewers by inviting international reviewers with expertise in their fields of research. Moreover, by replacing the previous associate editor system to section editor system, more efficient and expedited review process can be expected. Furthermore, I believe inviting world-renowned guest editors with exceptional expertise in their fields of research will be conducive to the quality control of Psychiatry Investigation. As for the issue of increasing of the impact factor of Psychiatry Investigation, again, a focus on qual- ity over quantity is imperative. As Dr. Heon-Jeong Lee mentioned in the previous editorial, the expected JCR impact factor for Psychiatry Investigation is 1.6 for 2019. ${ }^{1}$ I believe Psychiatry Investigation, with 16 years of its history, should dream for more. I will do my best to improve the submission process more user-friendly, and as mentioned above, a pool of capable reviewers is crucial for an effective editorial process, which ultimately leads to publication of good quality articles and increased citations. To achieve the aforementioned goals, financial resources are compulsory. In this regard, I humbly ask for the understanding of KNPA members on our decision to increase the article processing charge from USD 300 to USD 500.

I promise to spend the next two years with devotion and passion that all the previous Editors-in-Chief have shown, and I hope Psychiatry Investigation can represent what is more than a regional journal, a world-class journal where academic fervor is never extinguished. Lastly and most importantly, our plans and goals are meaningless without the support and encouragement of the KNPA members. The editorial board is always open to suggestions and criticisms, and the members are all welcome to propose ideas to improve the quality of Psychiatry Investigation. I must thank all the people who have devoted their time and efforts for Psychiatry Investigation, and I sincerely ask for your support for the journal and the new editorial board in the next two years.

ORCID iD

Hyun Kook Lim https://orcid.org/0000-0001-8742-3409

\section{REFERENCE}

1. Lee HJ. How to develop Psychiatry Investigation into a world class journal. Psychiatry Investig 2019;16(12):875-876.

(c) This is an Open Access article distributed under the terms of the Creative Commons Attribution Non-Commercial License (https://creativecommons.org/licenses/bync/4.0) which permits unrestricted non-commercial use, distribution, and reproduction in any medium, provided the original work is properly cited. 